Oscar Vera L.

\title{
REFLEXIONES SOBRE LA LITERATURA EN CHILE
}

EORICAMENTE, son dos las finalidades de la reflexión sobre la literatura: una es dar una visión histórica de sus formas y de su desarrollo, lo que constituye el objeto propio de la historia literaria, y la otra, que es objeto de la crítica propiamente dicha, consiste en juzgar las obras literarias desde el punto de vista de su valor estético.

A menudo, en la práctica, ambas finalidades se confunden, y casi siempre la segunda prevalece sobre la primera. No se concibe una historia de la literatura-si no es exclusivamente documental-que no implique juicios de valor, y no se concibe una crítica literaria verdaderamente eficaz que no se funde en los datos de la historia. Bueno y malo, meritorio y despreciable, son adjetivos que, cuando se habla o se escribe de literatura, pueden eludirse sólo en la más escueta enumeración bibliográfica.

Aun el espíritu más reacio a erigirse en juez de lo que estudia no puede eximirse de juzgar fatalmente en los asuntos literarios. Aun France, el más agudo de los impresionistas, que pretendía shablar de sí mismo a propósito de Hamlet y decía de Brunetière qu'il juge donc, puisqu'il est judicieux, no vacilaba en anonadar con sus juicios a Zola y al propio Brunetière.

Como en el campo de nuestra conducta el solo hecho de actuar en un sentido dado implica un juicio moral, en literatura el solo hecho de manifestar una preferencia o un gusto implica un juicio estético. El criterio según el cual se juzga puede variar del meramente dogmático, fundado en la religión o en la moral, al que se basa en la más amplia concepción psicológica o sociológica del arte, pero el hecho de juzgar subsiste. La historia literaria nació sólo para fundamentar estos jui- 
cios ineludibles, para darles el carácter de objetividad que perdieron con el descrédito de la preceptiva clásica, que ya encerraba sin embargo en sí un rudimento de concepción histórica. El método crítico de Sainte-Beuve no pretendía otra cosa que autorizar los juicios, hacerlos más comprensivos y más inteligentes al buscar su raíz en la vida del autor y en las circunstancias que rodearon el nacimiento de sus obras.

Así, dentro de cada literatura se establece una tabla de valores, se distribuyen las flexibles jerarquías entre las épocas, entre las obras y entre los autores, y se establecen los imprecisos límites de lo que podría llamarse el limbo literario, pasados los cuales una obra o un autor conserva sólo una mustia existencia en los catálogos de las bibliotecas o en las notas de alguna historia literaria bien documentada.

Ahora bien, si se conserva esta ineludible tendencia a juzgar cuando se reflexiona sobre nuestra literatura-como, en general, sobre la literatura de cualquier país latinoamericano-no podemos menos que atribuirnos el limbo literario de la cultura occidental. Ahí se nos coloca desde Europa, y ahí nos ha ratificado el juicio de muchos americanos.

Más que de una pura valoración estética, nuestra literatura es objeto de la curiosidad de los extranjeros que buscan en ella los balbuceos de una cultura naciente, o del fervor patriótico que escudriña, para exaltarlas, las glorias nacionales, o del afán objetivo de los historiadores que juzgan con criterio ecuánime una revolución, una epidemia o un movimiento literario.

¿Hasta qué punto seríamos capaces de soportar con buen éxito una valoración? ¿Según qué criterio habría de hacerse?

Una tabla de valores es patrimonio necesario de una cultura, no se concibe sin una larga acumulación de antecedentes sobre cuya base haya ido formándose, requiere la existencia de una tradición. Como nuestra cultura no es nuestra, aun en la medida en que nuestros hechos culturales nos pertenecen exclusivamente, debemos exponerlos a una tabla de valores ajena.

Cualquier manifestación de la cultura que entre nosotros observemos-arte, política, ciencia-nos parecerá gris, chata, uniformemente despreciable si no acomodamos nuestra mirada a un paisaje de proporción modesta: la tabla de valores se rompe, y se rompe con el estrépito lamentable del ridículo, cuando tratamos de aplicarla sin correcciones a lo nuestro.

Es lógico, pues, que dentro de esos moldes resulte vana toda tentativa de encontrar en nuestra producción literaria algo que sea verdaderamente grande, algo que sea sin desmedro comparable a lo que estamos habituados a recibir de Europa. 
Porque en literatura esta situación es quizás más patente que en otros asuntos: tenemos en la cultura occidental ejemplos abrumadores. Y como nuestros literatos, haciendo contadas excepciones, han tratado de competir con el espíritu europeo en igualdad de circunstancias antes que de concentrar su esfuerzo en los asuntos peculiares de América, los hechos que un observador desapasionado verifica no son alentadores: apenas si unos cuantos literatos, algunos sólo en parte de su obra, y con reservas, resisten la piedra de toque de los valores corrientes en la literatura occidental. Todo lo demás, salvo uno que otro libro aislado, tiene un simple valor de documento.

Pero considerar así los problemas de nuestra vida literaria es evidentemente injusto bajo más de un aspecto. Por muy estético que sea, nuestro punto de vista no puede ser exactamente el europeo. Y aunque parezcan discutibles las razones capaces de hacernos olvidar en parte los valores que nos obliga a aceptar con ella una cultura de la cual vivimos, nada ganaremos con declarar nuestra literatura un subproducto indigno de consideración.

La posición actual de los problemas literarios, si bien no puede redimirnos enteramente de nuestra inferioridad relativa, nos permite considerar por lo menos nuestra literatura desde un punto de vista que la revaloriza en otro sentido y le confiere una nueva importancia.

En efecto, como la moral, la estética ha ido perdiendo poco a poco su primitivo carácter metafísico, y en nuestros días se la vincula estrechamente a los fenómenos psicológicos y sociales que determinan sus problemas propios. La belleza ya no es considerada como un valor absoluto, como un paradigma supremo del cual deban desprenderse normas rigurosas, sino más bien como una resultante o como una función de los hechos artísticos en cuanto son formas del alma colectiva. Y si un determinado concepto del valor literario se precisa-con toda la vaguedad que exigen los asuntos estéticos-para Alemania o para Francia, es válido para nosotros en la medida en que participamos de los caracteres comunes a la cultura occidental, pero debe alterarse forzosamente en función de nuestras diferencias y modalidades propias.

Además, considerada en su conjunto, una literatura revela un alma colectiva singular y las diversas fases de su evolución, sus formas más íntimas, sus concepciones de la vida y del mundo. Así, si en un sentido estricto y racional buscamos en la literatura valores estéticos-que varían, por lo demás, con las diversas épocas, como todos los valores-en un sentido más 
amplio y humano encontramos en ella los rasgos típicos y salientes de un pueblo.

Obligados por una parte a servirnos de los valores de occidente para apreciar nuestras obras, ya que carecemos todavía de una tradición que nos permita fijar valores propios, no podemos eludir, por otra parte, la investigación de nuestras características nacientes a través de nuestras manifestaciones literarias. Por lo tanto, no es posible conformarse a aplicar indefinidamente a nuestra literatura un criterio occidental escricto, sin resignarse a reconocer nuestra incapacidad de crear formas culturales propias-y al decir así pienso más en latinoamérica que en Chile,- - sin resignarse a creer que cien años de vida política más o menos independiente y las poderosas influencias de la geografía y de la raza no han moldeado ni siquiera un esbozo de vida espiritual diferenciada.

Nuestra literatura es un hecho, todo lo poco satisfactorio que se quiera desde el punto de vista estético, pero es un hecho que contribuye a interpretarnos, a esclarecernos y a explicarnos como chilenos y como latinoamericanos. Antes que una condenación rotunda merece pues un análisis de las causas que la han determinado tal como es y el estudio objetivo de sus formas y de su evolución. Buscando las razones de sus defectos y de su inferioridad encontraremos la explicación de muchos problemas $y$, sobre todo, lograremos precisar hasta qué punto esa inferioridad y esos defectos son inevitables y prever las condiciones y las líneas generales de su futuro desarrollo.

La literatura expresa, conforme a procedimientos típicos que son el atributo peculiar del arte, los diversos aspectos de la vida del hombre y de lo que le es afín. Es, o una reproducción convencional de la vida en su complejidad concreta (novela, cuento, teatro), o una reflexión sobre la vida (poesía, ensayo) cuyo dominio va de la más vaga intuición subjetiva a la más precisa objetividad intelectual.

La vida del individuo y de la sociedad con toda la inagotable riqueza de sus hechos y de sus conflictos, y la naturaleza que encuadra la vida de los seres-telón de fondo sobre el cual realizan su existencia, conjunto de leyes biológicas a que está sometida-constituyen el objeto propio de la literatura, que el arte recrea y transforma. En cierto sentido, el arte consiste en crear sobre la base del mundo real un supermundo, más sencillo y comprensible, regido por leyes esquemáticas y convencionales $y$ en el cual la realidad, sintetizada y condensada 
en el espacio y en el tiempo, destaca en forma imprêsionante sus matices.

Así comprendida, como expresión de la vida en su totalidad, la literatura puede desarrollarse sólo en las sociedades que han logrado resolver hasta cierto punto los problemas más urgentes de su existencia. Toda reflexión de la vida sobre sí misma necesita tiempo disponible, holgura social, y es por esencia desinteresada y accesoria. El arte-cuya índole semejante a la del juego ha sido puesta tan a menudo en evidencia,-lo es más que ninguna otra.

Cuando la vida social ha tomado un cauce político y economico más o menos estable, aparecen las primeras manifestaciones literarias, y cuando cambian las circunstancias políticoeconómicas, $y$ con ello la vida social adquiere un ritmo y un contenido diferentes, cambia también el contenido de la literatura y sus preocupaciones se desplazan en el sentido que señalan las nuevas condiciones sociales.

Esto tiene entre nosotros una plena confirmación. El movimiento literario de 1842 es la consecuencia natural de la organización de la república realizada por Portales y se continúa casi invariablemente dentro de sus primeros moldes hasta el año de 1891 . La revolución anti-balmacedista, cuya importancia ha sido desdeñada por muchos, señala en Chile la crisis de la organización social creada por Portales y el nacimiento de otra que pugnaba por realizarse desde el fin de la guerra con el Perú.

La república autocrática y la república parlamentaria corresponden innegablemente a dos modalidades distintas de la sociedad chilena que han dejado huellas patentes en la literatura. Durante el imperio de la primera, la clase media, por un doble movimiento de ascenso y de descenso, se fué formando lentamente de la plebe holgada y de la aristocracia empobrecida. Bajo la segunda, la clase media llega al apogeo de su desarrollo, se realiza íntegramente. Antes de 1891, el poder político se restringe a una oligarquía vagamente asimilable a la nobleza del antiguo régimen, en que el apellido y la tradición prevalecen aún sobre el dinero. Después de 1891, domina una oligarquía plutocrática cuyos prejuicios de familia están ya en decadencia.

Es indispensable agregar a estos hechos sociales la influencia espiritual de los países europeos, que, si bien se hace sentir entre nosotros con muchos años de retraso y en forma aislada y caprichosa, ha determinado las líneas más generales de nuestra evolución política y cultural. Esta influencia proviene casi 
exclusivamente de España y de Francia. Hasta mediados del siglo XIX, Francia proporcionó los modelos teóricos de organización política, y España, cuya hegemonía cultural ejercida durante tres siglos y asentada en la religión y en el idioma no podía romperse fácilmente, preponderó en lo literario. Pero después, la independencia de la antigua metrópoli se reaiiza íntegramente, y es Francia el modelo que se trata de imitar en la filosofía, en las ciencias y en las letras, y el país cuya cultura ha influído más profundamente en América latina hasta la fecha.

El año de 1842 señala el nacimiento, no propiamente de nuestra literatura, sino de un interés fecundo por las letras y las ciencias. Bello, Sarmiento y Lastarria y sus discípulos y admiradores son los hombres en cuyas opuestas tendencias se encauza la inquietud intelectual provocada por la estabilización de la vida republicana. Bello enseño a los chilenos la lengua de que debían servirse y el gusto por una forma marcadamente clásica y por la investigación seria y metódica. Sarmiento les insinuó, a través de su personalidad bulliente y animada, el sentido romántico de la lucha contra la tiranía y la retórica, y Lastarria fomentó el interés por la especulación filosófica racionalista y verbal que entonces daba la medida de la profundidad.

Las manifestaciones culturales de ese tiempo giran en torno a la Universidad recién fundada y a las ideologías políticas antipeluconas que comienzan a diseñarse; tienen más un carácter académico y social que puramente artístico. En las primeras novelas de don Alberto Blest y en el periódico literario $\mathrm{La} \mathrm{Se}$ mana de los Arteaga Alemparte, alrededor de 1860 , podemos ver las primicias de nuestra actividad literaria, balbuceos forzosamente desordenados e imperfectos que las influencias española y francesa determinan en un reducido ambiente cultural.

La política era en aquel tiempo la actividad absorbente de los hombres ilustrados, y era el número de éstos tan escaso que la Universidad, única fuente de ilustración, apenas bastaba para proporcionar los congresales, altos empleados de los ministerios, agentes diplomáticos, etc., que exigía la marcha normal del país. No bien un individuo descollaba por sus condiciones intelectuales, era inmediatamente asimilado por la clase dirigente, en los raros casos en que no pertenecía ya a ella por su familia. Sólo después de 1857 , cuando se rompe la autarquía pelucona y comienza a tomar cuerpo la reacción liberal, la literatura parece fortificarse con la lucha, porque llega a ser tam- 
bién un medio de combate político. Aun las novelas folletinescas, sobre todo las de Ramón Pacheco, son más que nada un elemento de propaganda anticlerical.

Antes de 1891, no hay un soío escritor considerable que no haya estado estrechamente vinculado a la política. Jotabeche y Pérez Rosales, Lastarria y Bilbao, los hermanos Arteaga Alemparte y Manuel Blanco Cuartín, Vicuña Mackenna y Sotomayor Valdés, para no citar sino unos pocos, antes que escritores, antes que puros literatos, fueron hombres públicos. Y el prestigio que muchos de ellos adquirieron en su tiempo y que ahora suele parecer desproporcionado fué casi siempre un mero reflejo de su actuación circunstancial.

Si la poesía se libera en parte de las preocupaciones sociales, es por su índole personal y subjetiva, y si Blest Gana, el más grancịe de los literatos de, este período y hasta la fecha el más importante de nuestros novelistas, logró realizar una obra puramente literaria, es porque se educó en Francia y vivió la mayor parte de su vida en el extranjero.

Junto a esta subordinación de la literatura a la política, el auge extraordinario de la historia es otra de las características de este período. Y este auge no es debido sólo a la profusión de obras históricas, sino también a la acogida que tuvieron en el público, a tal punto que puede decirse que la historia ha sido en Chile casi el más popular de los géneros. Excluyendo a Jotabeche y a Blest Gana, los nombres más valiosos de nuestra literatura en el siglo pasado son de historiadores: Barros Arana, los Amunátegui, Vicuña Mackenna y Sotomayor Valdés. $Y$ si Blest Gana y Jotabeche hicieron literatura sobre la base de la historia y de las costumbres y deben el valor que corrientemente se atribuye a sus obras a la agudeza de su observación, encontramos en nuestros historiadores la misma tendencia profunda, aunque desde un punto de vista más científico y objetivo: el afán de la mentalidad colectiva por conocer los antecedentes y los hechos que presidieron su formación.

La urgencia de las luchas políticas, que hicieron concentrar en torno a las doctrinas de los bandos opuestos la mejor parte de la actividad intelectual, explican que en este primer período la producción puramente literaria haya sido tan escasa, y que sea necesario considerar y juzgar la restante en función de las circunstancias sociales que la provocaron. El típico desarrollo de la literatura histórica que caracteriza este tiempo nos aparece como una tendencia a buscar lo propio y lo diferente en la investigación concienzuda del pasado, como el primer intento valioso de formar una tradición de cultura, que 
carece todavía del ímpetu necesario que lo haga elevarse a la expresión depurada del arte.

En muy distintas condiciones se realiza nuestra literatura en el período siguiente. El enriquecimiento del país, la incorporación de la clase media a la vida de la cultura, el gran desarrollo de la instrucción pública, el progreso en los medios de comunicación con Norte América y Europa y la profunda evolución de la cultura de occidente cuya influencia se extiende con una intensidad enorme, son los principales hechos ocurridos alrededor de 1890 que explican las profundas diferencias que es dable observar entre la literatura de la república autocrática y la de la república parlamentaria. La ilustración se ha propagado profusamente. La política se confunde cada vez más con los negocios privados, se transforma también en un negocio más o menos turbio que no interesa ni apasiona como antes. La vida social ha perdido el noble tono de antaño, se va democratizando cada vez más. Bajo la clase media incorporada a la vida del estado. comienza a agitarse sordamente la masa del pueblo que hará su primera manifestación política en 1920. La riqueza del salitre basta para satisfacer medianamente a los políticos y para permitir la marcha ascendente del país sin graves trepidaciones. Además, el Parnaso, el Simbolismo, el Naturalismo, todas las escuelas literarias que prosperan sucesivamente en Francia a fines del siglo pasado y a comienzos del actual, la literatura rusa y las inquietudes modernas, irrumpen bruscamente entre nosotros, y aunque influyen en las más variadas y caprichosas formas, provocan una completa transformación de la literatura.

El ambiente es como nunca propicio para el desarrollo de las letras, $y$, en el hecho, la producción literaria aumenta de año en año. Sin embargo, es una discreta medianía, ni abiertamente despreciable ni capaz de conseguir lectores, la que predomina generalmente en la literatura chilena de este siglo. A pesar de todo, algunos poetas y unos cuantos nombres en la novela y en el cuento descuellan y tienen calidad digna de ser considerada.

Probablemente es la poesía, como la historia en el período anterior, el género que ha producido obras más valiosas en estos últimos cuarenta años, y el que más profundamente ha penetrado en el público. Nombres como Pedro A. González, Pezoa Véliz, Magallanes Moure, Carlos Mondaca, Gabriela Mistral, Pablo Neruda, junto con otros de obra más reducida, pero de apreciable valor poético, ilustran sobradamente nuestro aserto. Por nuestra poesía corre en cauce profundo una buena 
parte de lo que hay de más típico en nuestra alma y en nuestra literatura, y se explica, porque el poeta, más intuitivo que intelectual, puede escuchar más íntimamente las hondas voces del instinto y de la raza. La tristeza irreconciliable- no la tristeza llorona de los románticos, sino casi un verdadero sentido de la vida como cosa triste- una sensualidad turbia y sin alegría, el impreciso sentimiento de una vida inútil, todo eso expresado más bien con sobriedad que con arranques líricos, se desprende de los versos de nuestros mejores poetas. Las influencias extranjeras no han podido prevalecer del todo contra lo que hay de característico y diferente en nuestra alma racial, que aun no se delinea claramente, pero que en la poesía-y ya se puede observar en la prosa uno que otro rasgo semejantecomienza a liberarse y a encontrar el modo propio de su expresion.

La novela, el cuento y el ensayo han sido profusamente cultivados. Algunos libros de valor y las obras de escritores como Baldomero Lillo, Pedro Prado, Mariano Latorre, Joaquín Edwards, Eduardo Barrios y unos pocos que son todavía una promesa, resisten sin grave daño una apreciación estricta y revelan una literatura que tiende a ser original y a libertarse hasta donde es posible de la tutela de occidente. Son lo más representativo de nuestra prosa y destacan brillantemente sobre la desoladora mediocridad. Pero unos pocos buenos libros que, por una $u$ otra causa y a pesar de su mérito, apenas transcienden los límites regionales y un público reducido, no constituyen exclusivamente una literatura. El resto de la producción escrita con intenciones literarias merece también ser considerado, y merece sobre todo que se esclarezcan las razones de su inferioridad.

Un mal entendido sentimiento de lo criollo, que se limita muchas veces a los aspectos más superficiales, como la descripción convencional de usos y costumbres y la reproducción del lenguaje típico de los campesinos, la falta de originalidad con respecto de la literatura europea, la ausencia de inquietud, de grandeza y de sentido humano, o, simplemente, el mal gusto, la cursilería, y la ignorancia del idioma y de los procedimientos del estilo, son las cualidades más impresionantes del grueso de la producción literaria.

Sería absurdo pedir que una literatura en formación como la nuestra produjera sólo obras de primer orden, pero es preciso reconocer que seguramente en ninguna parte del mundo se publican libros tan malos, tan desprovistos del más leve mérito como los que aparecen con bastante frecuencia en los países 
de latino-América; y es preciso reconocer también que en ninguna parte hay una especie de críticos más benévola, tal vez porque estima que la producción de estos países jóvenes debe ser benignamente juzgada, como juzgan los mayores las gracias de los niños. Si bien la abundancia de malos escritores contribuye a destacar a los buenos y a los tolerables, no deja de impresionar desfavorablemente al público y de arraigar en él el prejuicio de que toda la literatura indígena es semejante. Sin embargo, todos estos hechos, que anotamos tal vez con excesivo rigor, tienen sus causas determinantes y evitables.

La instrucción humanística secundaria, y aun la universitaria, apenas permite asomarse al umbral de los problemas. El estudio corriente que se hace de la filología, de la filosofía, de la literatura y de la historia es espléndidamente superficial y son muy pocos los que lo profundizan por su cuenta. Las deficiencias de la enseñanza humanística oficial son una de las causas, y no despreciable, no sólo de la abundancia de obras injustificables y de los más fáciles blancos que nuestros escritores presentan a la crítica, sino también de la falta de "ambiente cultural» de que tan a menudo nos lamentamos.

Escribir es un oficio como cualquiera otro. Exige vocación y aprendizaje, sobre todo aprendizaje, que en este oficio es imprescindible. Entre nosotros, donde la vocación abunda y el aprendizaje generalmente se desdeña por inútil y por el escaso escepticismo con respecto a sus méritos que caracteriza al americano inteligente, florecen todos los vicios del dilettantismo, de la improvisación, de la incompetencia técnica.

La perseverancia en el cultivo de las letras constituye entre nosotros la excepción. Es una veleidad de adolescente, complemento necesario del amor romántico y de las primeras rebeldías, lo que ha engendrado el mayor número de nuestras producciones. Y casi siempre su calidad corre parejas con la solidez de la vocación que las inspira. Los treinta años son la barrera que muy pocos de nuestros literatos han podido salvar. Por eso son tan escasas las obras de madurez, en que a la riqueza de experiencias vitales se sume la maestría de la expresión adquirida en muchos años de constante ejercicio literario.

Además, si no es en el periodismo, y en casos muy contados, no se concibe al hombre que viva exclusivamente de su pluma. El «lamentable oficio de las letras», como ha dicho un escritor norteamericano, ofrece entre nosotros tan poca compensación económica y confiere tan reducido prestigió que los profesionales de la literatura pueden contarse en América latina con los dedos de la mano. 
Una literatura no existe sólo cuando existen escritores; requiere la colaboración, la cooperación, pasiva hasta cierto punto, pero imprescindible, del lector. La obra de arte no vive ni se realiza íntegramente mientras no ha encontrado un eco en cierta masa que siente y reconoce en ella la expresión de sus propios impulsos, deseos o inquietudes. Un libro que no se lee es un esfuerzo inútil, una lamentable equivocación, el discurso de un charlatán que nadie escucha.

Nuestra literatura, sin llegar al extremo $y$ absoluto aislamiento, es una literatura que casi no se lee. El público americano lee sin embargo, y aun puede decirse que lee bastante. Pero los escritores nacionales no le interesan. Tiene contra ellos un sólido prejuicio, que deriva seguramente de su desdén por todo lo autóctono y de su admiración incondicional a lo europeo, pero que no por eso contribuye menos a formar en torno a nuestra literatura una atmósfera hostil o indiferente. Si el público no paga los libros nacionales y paga en cambio los extranjeros, por mucho snobismo o espíritu cosmopolizante que quieramos ver en ello, es prudente reconocer que el hecho existe, y que no se puede culpar al público lisa y llanamente de incultura o de ignorar, por sistema, méritos positivos. O pensamos que nuestro público es inculto-y el auge del comercio de libros parece demostrar lo contrario-o que nuestra literatura no le ofrece casi nada digno de interés.

Si alguien debe romper este verdadero círculo vicioso en que se debaten nuestras letras, no es el público, sino los escritores. A ellos corresponde dignificar su oficio, defenderlo de los aficionados y de los literatos ocasionales, abandonar los caminos trillados y explotar los abundantísimos temas en que solamente pueden ser originales y que hasta la fecha están casi intactos.

El alma individual del americano no puede ciertamente ofrecer problemas tan complejos y ricos a la literatura como el alma europea, porque carece todavía de forma propia, de modalidades generales enérgicamente diseñadas que permitan considerarla como una entidad diferente. Por eso todo esfuerzo de literatura personal y subjetiva, a que casi siempre tiende el marcado individualismo criollo, se expone a no ser original y a parecer mezquino frente a las obras de los grandes maestros de occidente. Sólo en los conflictos entre la raza y la tierra, en la modificación profunda que la geografía impone al alma social, en la lucha contra la naturaleza virgen para asentar en ella el dominio de la civilización, en las peripecias de la formación política de estos pueblos, hay temas verdaderamente grandes, dignos del esfuerzo de nuestros mejores escritores y 
capaces de interesar al público. Obras como Civilización y Barbarie, Doña Bárbara, La Vorágine, Los de abajo, Don Segundo Sombra no tienen otra inspiracion, y junto con ser de las mejores que ha producido nuestra literatura, son las primeras epopeyas sobre cuya base se formará una tradición literaria verdaderamente americana.

En Chile abundan los motivos literarios del más alto interés, y si bien algunos de nuestros escritores los han destacado en sus obras, no han sido tratados todavía con la amplitud y la profundidad que merecen. La vida de los mineros en la pampa salitrera y en las provincias de Atacama y Coquimbo, las guerras de la frontera araucana y la conquista pacífica del sur que se realizó entre 1880 y 1915 , el mar, la historia de la independencia y de la guerra a muerte, la vida urbana, el nacimiento de las masas a la vida política en estos últimos años, son elementos originales de nuestra nacionalidad, algo que nos es propio, y tienen una intensidad de vida y una fuerza épica que aun no ha sido puesta de relieve.

Una grenovación de nuestra literatura que tiendą a diferenciarla nítidamente de la europea por el contenido de sus producciones, que eleve su calidad y logre conquistar el vasto auditorio a que tiene derecho, requiere una renovación paralela de la crítica literaria.

En rigor, es aventurado hablar de la existencia de crítica literaria en Chile. Hasta aquí, lo que se ha escrito sobre libros y autores ha carecido en general de orientaciones definidas que favorezcan el desarrollo de la literatura por su escasa influencia en los escritores y en el público, por su carácter circunstancial, a menudo ajeno a lo estrictamente literario. Los críticos, o han puesto su pluma al servicio de su religión o de su ideología política, o se han dejado llevar en sus apreciaciones por el encono personal, por las conveniencias sociales o por respetables sentimientos de amistad, o se han limitado a un impresionismo desorientador y caprichoso. Carecen corrientemente de ilustración literaria-que si conviene al literato es imprescindiblę para el crítico-de buen gusto y de un criterio definido para juzgar las obras nacionales. Su producción abundantísima ha quedado dispersa en diarios. y revistas, y, en la mayoría de los casos, no merece ser reunida.

Entre lo poco útil que se ha hecho hay dos o trés obras bibliográficas y unas pocas monografías y reseñas de historia literaria. En lo que a crítica y a historia de la literatura se refiere, todo o casi todo está por hacer. Hay materiales en 
abundancia y una misión por realizar que sólo se ha intentado raramente: revalorizar y hacer la historia de la literatura chilena, apartando para los eruditos y para los historiadores curiosos lo que tiene un mero valor documental, $y$ poniendo de relieve, con un criterio estricto, aquellos de nuestros valores que positivamente existen; comprender que no es posible juzgar las obras nacionales con el mezquino espíritu de círculo o con la benevolencia excesiva con que ha solido hacerse, sin condenar nuestra literarura al estancamiento y a la ignorancia del público, y contribuir a formar lentamente una tradición que contrarreste la dispersión y la discontinuidad de los esfuerzos literarios, y en la que puedan reconocerse el público y los escritores.

Formar esta tradición literaria chilena y latinoamericana es formar propiamente nuestra literatura. No temamos que la obra de valor universal que pudiera surgir entre nosotros pueda sentirse cohibida porque nuestra literatura tiene un cauce. Lo que debemos temer es la perseverancia en el desorden y en el caos, es la originalidad tan variada y tan poco valiosa que impide comparar entre sí a nuestros escritores, es la diversificación de lo anárquico, no de lo organizado, de lo que se agita, no de lo que vive.

Mientras todo eso subsista, mientras bajo las diversas apariencias literarias no podamos reconocer un alma común que pugna por expresarse, no podremos hablar de una literatura nuestra. Para tenerla, es preciso salir en busca de esa alma, descubrirla entre nosotros, en el fondo de nosotros mismos, en nuestro paisaje, en nuestra naturaleza y en nuestra vida y en sus luchas, donde seguramente ya palpita y busca también su forma, y revelarla transformada en el supermundo coherente del arte. 